\title{
Deltamethrin resistance in Rhipicephalus sanguineus and Rhipicephalus (Boophilus) microplus tick population in Kerala
}

\author{
Amrutha Anand', Bindu Lakshmanan'², T.A. Kajal ${ }^{3}$, Siju Joseph ${ }^{4}$, \\ (iD) \\ T.V. Aravindakshan ${ }^{5}$ and Jain Jose \\ School of Applied Animal Production and Biotechnology, College of Veterinary and Animal Sciences, \\ Mannuthy, Thrissur, Kerala. Kerala Veterinary and Animal Sciences University
}

Citation: Anand, A., Lakshmanan, B., Tambe, K.A., Joseph, S., Aravindakshan, T.V. and Jose, J. 2021.Deltamethrin resistance in Rhipicephalussanguineusand Rhipicephalus (Boophilus) microplustick population in Kerala. J. Vet. Anim. Sci.52(1): 19-25.

DOI: https://doi.org/10.51966/jvas.2021.52.1.19-25

Received: 22.09.2020

Accepted: $10 \cdot 10.2020$

Published: 01.01.2021

\section{Abstract}

The study evaluated deltamethrin resistance in Rhipicephalus sanguineus and Rhipicephalus (Boophilus) microplus tick populations of Kerala in India, using larval packet test (LPT). Dose response data were analysed by the probit method, the $L C_{50}$ and $L C_{95}$ of deltamethrin against ticks were determined by applying regression equation analysis to the probit-transformed data of mortality. In $R$. sanguineus, 50 per cent of isolates were found resistant at discriminating dose $(600$ ppm) by larval packet test. The $p$ value obtained upon regression analysis was $<0.05$ and was considered as significant. $A$ majority of $R$. (B.) microplus were found to be susceptible to deltamethrin. However, these susceptible isolates survived doses which were twice the recommended doses (1.25 ppm - 100 ppm). The $p$ value of isolates except isolate 1 and 5 were $<0.05$ and statistically significant. The results highlight acaricide resistance to be one of the reasons for the alarming prevalence of tick-borne haemoparasites in Kerala and demand urgent interventions to ameliorate the resistance by alternate control strategies.

\section{Keywords}

Rhipicephalus sanguineus, Rhipicephalus (Boophilus) microplus, Larval Packet test

Ticks are considered harmful obligate blood-sucking ectoparasites of medical and veterinary importance, as they not only transmit economically important infections to animals but also play a major role in zoonotic pathogen transmission to humans (Balasubramanian et al., 2019).

1. MSc Scholar (Corresponding Author: amruthaanand1010@gmail.com)

2. Associate Professor, Department of Veterinary Parasitology

3. MVSc Scholar, Department of Veterinary Parasitology

4. Assistant Professor, Department of Veterinary Microbiology

5. Director, CASAGB and SAAPBT, CVAS, Mannuthy

6. Research Assistant, Department of Animal Genetics and Breeding, CVAS, Mannuthy

Copyright: $(92021$ Amrutha et al. This is an open access article distributed under the terms of the Creative Commons Attribution 4.0 International License (http://creativecommons.org/licenses/by/4.0/), which permits unrestricted use, distribution, and reproduction in any medium, provided the original author and source are credited. 
In India, the warm humid climate favours the propagation and perpetuation of ticks (Haque et al., 2014; Rani et al., 2018).

Rhipicephalus (Boophilus) microplus, one host cattle tick, is the most prevalent tick causing considerable economic loss in dairy cattle worldwide (Guerrero et al., 2001). They transmit rickettsial diseases such as ehrlichiosis and anaplasmosis and protozoal diseases such as babesiosis, besides inflicting direct effects on the animal per se through blood loss. Rhipicephalus sanguineus, a three-host brown dog tick, transmits several protozoan parasites like Babesia canis, Ehrlichia canis and Leishmania infantum (Dantas-Torres, 2008). Ticks and tick-borne diseases (TBDs) are a major constraint in the development and improvement of the livestock industry (Ahamed et al., 2007). Chemical acaricides play a vital role in tick control. However, the indiscriminate and frequent use of acaricides has led to drug and multidrug resistance against almost all commercially accessible acaricides. Monitoring of ticks and drug efficacy are important to detect resistance at an early stage to help minimize the spread of resistance and to document the distribution pattern of acaricide resistance (Lovis et al., 2011).

The common acaricides in use include synthetic pyrethroids, organophosphates, organochlorines, carbamates, amidines, macrocyclic lactones and formamidines. Synthetic pyrethroids (SP) are highly biodegradable and not very toxic to mammals and had been introduced in the 1960s and 1970s. Already in the late 1980s, resistance to synthetic pyrethroids (SP) had been reported in Brazil and Australia, and it was reported in Mexico in 1994. Nowadays SP resistance is extremely common and prevalent world over (Yessino et al., 2016). In South India, deltamethrin resistance to cattle ticks, $R$. (Boophilus) annulatus and $R$. (Boophilus) microplus has been reported (Jyothimol et al., 2014; Lenka et al., 2016). While, in North India, acaricide resistance has been widespread against flumethrin, fipronil (Shyma et al., 2015) and deltamethrin (Abdullah et al., 2012; Shyma et al., 2015) in different tick species infesting large ruminants. In India, there have not been many studies on drug resistance in $R$. sanguineus. Mathivathani et al. (2011) reported 64.72 per cent resistance against flumethrin and 59.35 per cent resistance against deltamethrin in $R$. sanguineus in Chennai by using adult immersion tests.

Among the various bioassay techniques developed for recognizing acaricide resistance in ticks, larval packet technique (LPT) is a reliable method (Stone and Haydock, 1962). The Food and Agriculture Organization of the United Nations (FAO) had adopted this method as the standard method for the detection and measurement of acaricide resistance (Morgan et al., 2009). Singh et al. (2015) reported that the acaricide resistance frequency is higher in one host ticks, since a much larger portion of the entire population of such species are exposed to chemical encounter at any one time than multi host ticks.

In the light of high prevalence of tickborne pathogens among domestic animals in Keralaand scanty reports of acaricide resistance in ticks, this study particularly focused upon the assessment of deltamethrin resistance in cattle and dog ticks by bioassay.

\section{Materials and methods}

\section{Collection of ticks}

Fully engorged adult female $R$. sanguineus and $R$. (B.) microplus ticks were collected from animals presented to veterinary hospitals, as well as from private kennels and farms in Thrissur district of Kerala. Kerala is a southern state of India, spanning an area of approximately $3,032 \mathrm{~km}^{2}$, characterised with a tropical climate with an average annual temperature of $27.6^{\circ} \mathrm{C}$ and the relative humidity being generally over 70 per cent. The collected ticks were cleaned with distilled water, dried on an absorbent paper, identified by morphological keys (Sen and Fletcher, 1962) and sampled in separate bottles. Each bottle containing around three to five engorged female ticks were labelled and closed with a muslin cloth to maintain aeration and moisture. For egg laying and hatching, the bottles were placed in a desiccator maintained with a temperature of $28^{\circ} \mathrm{C}$ and relative humidity of 85 per cent. Nearly 2-10 days were 
taken for egg laying (Fig. 1), while 15-21 days were required for the eggs to hatch into larvae. The hatched out tick larvae were maintained for 14-21 days in desiccators for performing larval packet test (LPT).

Fig. 1 Egg mass of R. (B.) microplus

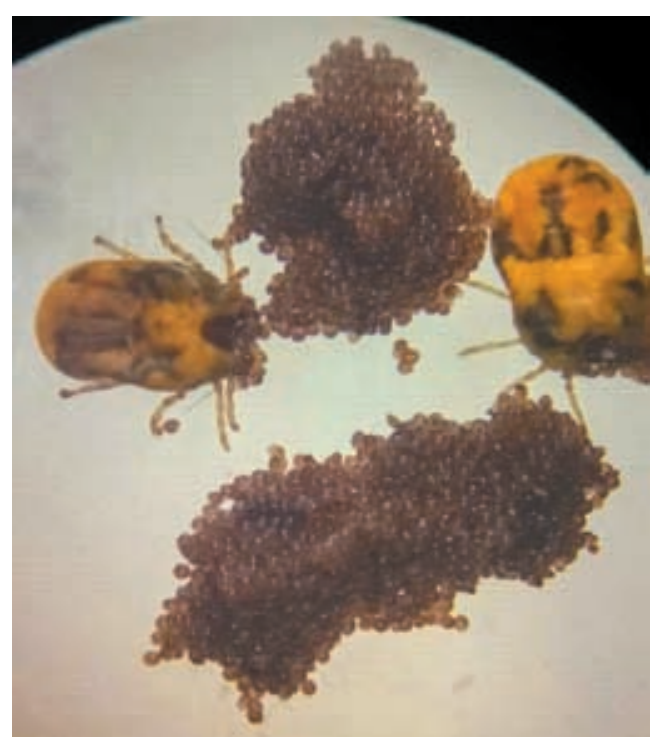

\section{Protocol of LPT}

The LPT was performed as per the recommendations of FAO (2004) with minor modifications. Technical grade 100 per cent pure deltamethrin (PESTANAL, Sigma- Aldrich, USA) was used for the bioassay. Working concentrations of 240 ppm, 120 ppm, 60 ppm, $30 \mathrm{ppm}$ of deltamethrin were prepared by serially diluting the stock concentration with distilled water. Bioassay was also performed with discriminating dose (DD) of deltamethrin (600 ppm). Rectangular packets (8 cm x 4.2 $\mathrm{cm}$ ) were prepared using Whatman filter paper No.1. These packets were carefully impregnated with $500 \mu \mathrm{L}$ of the above solutions and allowed to dry at room temperature. Distilled water was used as the control. Three replicates of each treatment were tested. Approximately, 100 numbers of 14-21 day old live larvae were deposited into each dried packet. The open end of these packets were sealed with bulldog clips and kept in desiccators at room temperature for $24 \mathrm{~h}$. After the incubation period, the packets were opened and the number of dead and live larvae were counted manually to estimate the per cent mortality.

\section{Statistical analysis}

Dose response data were analysed by the probit method (Finney, 1952). The 50 per cent $\left(\mathrm{LC}_{50}\right)$ and 95 per cent $\left(\mathrm{LC}_{95}\right)$ lethal concentrations of deltamethrin against $R$. sanguineus and $R$. (B.) microplus were determined by applying regression equation analysis to the probit-transformed data of mortality with regression analysis. A value of $p<$ 0.05 was considered as statistically significant.

\section{Results and Discussion}

The study was conducted to evaluate deltamethrin resistance in $R$. sanguineus and $R$. (B.) microplus, the most economically important ectoparasites of dogs and cattle, respectively. Per cent mortality of larvae was assessed at different deltamethrin concentrations. The isolates were considered resistant, if mortality of $R$. sanguineus and $R$. (B.) microplus treated with discriminating dose (DD: $600 \mathrm{ppm}$ ), were below 90 per cent.

Analysis of probit transformed mortality of $R$. sanguineus against log concentration of deltamethrin is given in Table 1. Isolate 5 and 6 of $R$. sanguineus showed 100 per cent mortality even at the lowest concentration of deltamethrin and hence $\mathrm{LC}_{50}$ and $\mathrm{LC}_{95}$ were not derived. Isolate 4 had the least $\mathrm{LC}_{50}(8.71 \mathrm{ppm})$ and $\mathrm{LC}_{95}$ (2089.29 ppm). Isolates 1, 2 and 3 were shown to be resistant at DD. Isolate 4,5 and 6 were considered susceptible and mortality at DD was $>90$ per cent. The $\mathrm{LC}_{95}$ of all the resistant isolates were higher than the recommended acaricidal dose of deltamethrin (1.25 ppm - 100 $\mathrm{ppm})$. The $p$ value obtained upon regression analysis with $R$. sanguineus isolates was $<0.05$ and was considered significant.

The $\mathrm{LC}_{50}$ and $\mathrm{LC}_{95}$ values of different isolates of $R$. (B.) microplus (Table 2) showed that isolate 1 had the lowest LC $_{50}(16.98 \mathrm{ppm})$ and $\mathrm{LC}_{95}(131.82 \mathrm{ppm})$, while the highest $\mathrm{LC}_{50}$ (223.87 ppm) and LC $_{95}$ (602.56 ppm) were observed for isolate 5. Except for isolate 5, all other $R$. (B.) microplus isolates were found to be susceptible to deltamethrin. However, the $\mathrm{LC}_{50}$ and $\mathrm{LC}_{95}$ of all isolates were higher than the recommended dose. In susceptible isolates the least LC $_{50}$ observed was 16.98 and LC $_{95}$ 
Table 1 Probit analysis of LPT with $R$. sanguineus

\begin{tabular}{|c|c|c|c|c|c|c|}
\hline Tick & Slope \pm SE & $\mathbf{R}^{2}$ value & $\begin{array}{l}\mathrm{LC}_{50} \text { (in } \\
\mathrm{ppm} \text { ) }\end{array}$ & $\begin{array}{c}L_{C_{95}} \\
\text { (in ppm) }\end{array}$ & $P$ value & $\begin{array}{c}\text { Mortality } \% \\
\text { at DD }\end{array}$ \\
\hline Isolate 1 & $0.6742 \pm 0.0755$ & 0.9648 & 107.15 & 26302.68 & 0.002 & $69.86 \%$ \\
\hline Isolate 2 & $0.7624 \pm 0.0615$ & 0.9814 & 467.74 & 67608.29 & 0.001 & $54.80 \%$ \\
\hline Isolate 3 & $0.4846 \pm 0.0697$ & 0.9430 & 26.30 & 67608.29 & 0.005 & $76.60 \%$ \\
\hline Isolate 4 & $0.6955 \pm 0.1548$ & 0.8738 & 8.71 & 2089.29 & 0.019 & $91.02 \%$ \\
\hline Isolate 5 & \multirow{2}{*}{\multicolumn{5}{|c|}{$\begin{array}{c}\text { Not calculated since } 100 \% \text { mortality was observed with lowest } \\
\text { concentration }\end{array}$}} & $100 \%$ \\
\hline Isolate 6 & & & & & & $100 \%$ \\
\hline
\end{tabular}

Table 2 Probit analysis of LPT with $R$. (B.) microplus

\begin{tabular}{|c|c|c|c|c|c|c|}
\hline Tick & Slope \pm SE & $\mathbf{R}^{2}$ value & $\begin{array}{c}\mathbf{L C}_{50} \\
\text { (in ppm) }\end{array}$ & $\begin{array}{c}\mathbf{L C}_{\mathbf{9 5}} \\
\text { (in ppm) }\end{array}$ & P value & $\begin{array}{c}\text { Mortality } \% \\
\text { at DD }\end{array}$ \\
\hline Isolate 1 & $1.8852 \pm 0.8352$ & 0.6363 & 16.98 & 131.82 & 0.105 & $100 \%$ \\
\hline Isolate 2 & $2.0819 \pm 0.2085$ & 0.9716 & 51.29 & 309.03 & 0.002 & $99.11 \%$ \\
\hline Isolate 3 & $2.0801 \pm 0.5285$ & 0.8418 & 26.92 & 165.95 & 0.028 & $98.69 \%$ \\
\hline Isolate 4 & $1.6788 \pm 0.4772$ & 0.8095 & 24.55 & 229.09 & 0.037 & $98.28 \%$ \\
\hline Isolate 5 & $3.8499 \pm 1.4578$ & 0.7054 & 223.87 & 602.56 & 0.075 & $81.58 \%$ \\
\hline Isolate 6 & $5.4367 \pm 1.1416$ & 0.8862 & 151.36 & 301.99 & 0.016 & $100 \%$ \\
\hline
\end{tabular}

was 131.82. The $p$ value of analysis with all $R$. (B.) microplus isolates except isolate 1 and 5 were less than 0.05 and statistically significant.

Resistance of ticks against acaricides could be monitored by using various bioassays, such as larval packet test (LPT), adult immersion test (AIT), larval tarsal test (LTT) and larval immersion test (LIT) (FAO, 2004). Acaricide resistance in ticks is an inherited phenomenon, defined as a reduction in susceptibility of ticks to the acaricide when it is used at the recommended dose (FAO, 2004). Fular et al. (2018) observed that the resistance level and mechanisms of resistance development varied in different parts of the world. Hence, regular monitoring of resistance is an inevitable control strategy in areas where tick and tick-borne parasites continue to pose a significant threat to livestock population. Our study established that deltamethrin resistant phenotypes persisted among tick populations infesting cattle and dogs of Kerala. Bioassay using LPT revealed that at discriminating dose, 50 per cent of $R$. sanguineus were resistant to deltamethrin, while 83 per cent of $R$. (B.) microplus were susceptible. However, these susceptible isolates survived doses that were twice the recommended doses of 1.25 ppm to 100 ppm (Sandhu, 2006).
Resistance status of $R$. (B.) microplus ticks against synthetic pyrethroids was globally studied using the FAO recommended larval packet test (Rosario-Cruz et al., 2009; Abdullah et al., 2012; Domingues et al., 2012; Shyma et al., 2013; Shyma et al., 2015). Lovis et al. (2012) assigned phenotype resistance to tick population based on three criteria: Survival rate at $D D$, resistance ratio $(R R) 50$ and $R R 90$. The population was designated resistant when their survival rate at DD was greater than 10 per cent or when the RR50 and RR90 were above four. In the present study, all $R$. (B.) microplus isolates, except isolate 5 were found susceptible, since mortality per cent was above 90 per cent at DD. The observed $\mathrm{LC}_{50}$ and $\mathrm{LC}_{95}$ of deltamethrin in susceptible tick population were much lower than that reported for resistant isolates (Shyma et al., 2012; Aboelhadid et al., 2018).

In Kerala, Jyothimol et al. (2014) had d a low level of deltamethrin resistance in cattle ticks with $\mathrm{LC}_{50}$ and $\mathrm{LC}_{95}$ values being $2.15 \mathrm{ppm}$ and $52.24 \mathrm{ppm}$, respectively in susceptible isolates of $R$. (B.) microplus, while those for $R$. (B.) annulatus were $2.11 \mathrm{ppm}$ and $34.75 \mathrm{ppm}$, respectively. In Uttar Pradesh, a north Indian state, LPT to detect acaricide resistance revealed that the $\mathrm{LC}_{99}$ values of fenvalerate and fipronil were $2007.0 \mathrm{ppm}$ and $4.8 \mathrm{ppm}$, respectively, while that of coumaphos 
and malathion, that were highly toxic to larvae, yielded $\mathrm{LC}_{99}$ values as low as $28.4 \mathrm{ppm}$ and 55.9 ppm, respectively (Kumar et al., 2015). The $\mathrm{LC}_{50}$ and $\mathrm{LC}_{95}$ values of deltamethrin acaricide against susceptible lines of Hyalomma anatolicum in the Indian cattle population were $11.7 \mathrm{ppm}$ and $34.9 \mathrm{ppm}$, respectively by LPT, as reported by Shyma et al. (2012). Shyma et al. (2015) reported $\mathrm{LC}_{50}$ and $\mathrm{LC}_{95}$ values of deltamethrin against resistant $R$. (B.) microplus isolates in North Gujarat to be 75.24 ppm and 367.74 ppm, respectively. Lenka et al. (2016) observed a wide variation (2.4 ppm-13.8 ppm) in the $\mathrm{LC}_{50}$ values in $R$. (B.) microplus isolate collected from South Indian states which was lower than that for North Indian isolates. Perusal of literature suggests that cattle ticks are resistant to almost all commercially available acaricides in India (Sharma et al., 2012; Shyma et al., 2013; Kumar et al., 2014; Singh et al., 2015; Lenka et al., 2016). The global situation is not different. The resistant Ehanasia population of $R$. annulatus showed a high $\mathrm{LC}_{50}$ value of $100 \mathrm{ppm}$ (Aboelhadid et al., 2018) against deltamethrin. Domingues et al. (2012) reported resistance to cypermethrin by LPT, since resistance ratio (RR) between 16.0 to 25.0 and 85.7 per cent were resistant to chlorpyriphos because RR value ranged from 2.2 to 15.6. Santos et al. (2013) observed wide variation of $\mathrm{LC}_{50}$ values $(264.9 \mu \mathrm{g} / \mathrm{mL}$ - 9923.9 $\mu \mathrm{g} / \mathrm{mL}$ ) in resistant field isolates in Brazil.

In South India, apart from the report of Mathivathani et al. (2011) in Tamil Nadu, deltamethrin resistance has not been studied in $R$. sanguineus isolates. The present study is the first report of acaricide resistance in dog ticks in Kerala state and it is identified that 50 per cent of $R$. sanguineus population in the state, selected for study, exhibited a mortality ranging from 53 to 77 per cent, at DD and were resistant to deltamethrin. The $\mathrm{LC}_{50}$ value of deltamethrin against susceptible $R$. sanguineus isolate was 8.71 ppm. Studies by Miller etal. (2002) revealed a resistance ratio of 7.3 against amitraz in a Panamanian strain of $R$. sanguineus by using LPT bioassay (Miller et al., 2002).

The current investigation showed that deltamethrin resistance in Kerala is comparatively higher in the three host ticks
(R. sanguineus) than among one host ticks ( $R$. (B.) microplus). The high prevalence of tickborne canine haemoparasites in this part of South India (Jain et al., 2017; Wahlang et al., 2019) despite the intensive use of deltamethrin, could be due to widespread drug resistance in the tick population. This necessitates studies on alternate control strategies, incessant monitoring and strategic application of other acaricides to control the tick population in this geographical area.

\section{Acknowledgement}

The authors gratefully acknowledge the technical support of Kerala Veterinary and Animal Sciences University, Pookode, Kerala, India for conducting the research.

\section{References}

Abdullah, S., Yadav, C.L. and Vatsya, S. 2012. Esterase profile of Rhipicephalus (Boophilus) microplus populations collected from Northern India exhibiting varied susceptibility to deltamethrin. Exp. Appl. Acarol. 58(3): 315-325.

Aboelhadid, S.M., Arafa, W.M., Mahrous, L.N., Fahmy, M.M. and Kamel, A.A. 2018. Molecular detection of Rhipicephalus (Boophilus) annulatus resistance against deltamethrin in middle Egypt. Vet Parasitol. Reg. Stud. Reports. 13: 198204.

Ahmed, J., Alp, H., Aksin, M. and Seitzer, U. 2007. Current status of ticks in Asia. Parasitol. Res. 101(2): 159-162.

Balasubramanian, R., Yadav, P.D., Sahina, S. and Nadh, V.A. 2019. Distribution and prevalence of ticks on livestock population in endemic area of Kyasanur forest disease in Western Ghats of Kerala, South India. J. Parasit. Dis. 43(2): 256-262.

Dantas-Torres, F. 2008. The brown dog tick, Rhipicephalus sanguineus (Latreille, 1806) (Acari: Ixodidae): from taxonomy to control. Vet. Parasitol. 152(3-4):173185. 
Domingues, L.N., Brasil, B.D.S.A.F., de Paiva Bello, A.C.P., da Cunha, A.P., de Barros, A.T.M., Leite, R.C., Silaghi, C., Pfister, K. and Passos, L.M.F. 2012. Survey of pyrethroid and organophosphate resistance in Brazilian field populations of Rhipicephalus (Boophilus) microplus: Detection of C190A mutation in domain II of the para-type sodium channel gene. Vet. Parasitol. 189(2-4): 327-332.

FAO (2004) Guidelines resistance management and integrated parasite control in ruminants, Rome.

Finney DJ (1952) Probit analysis: a statistical treatment of the sigmoid response curve. Cambridge university press, Cambridge.

Fular, A., Sharma, A.K., Kumar, S., Nagar, G., Chigure, G., Ray, D.D. and Ghosh, S. 2018. Establishment of a multi-acaricide resistant reference tick strain (IVRI-V) of Rhipicephalus microplus. Ticks Tick Borne Dis. 9(5): 1184-1191.

Guerrero, F.D., Davey, R.B. and Miller, R.J.2001. Use of an allele-specific polymerase chain reaction assay to genotype pyrethroid resistant strains of Boophilus microplus (Acari: Ixodidae). J. Med. Entomol. 38(1): 44-50.

Haque, M., Singh, N.K. and Rath, S.S. 2014. Effect of various acaricides on hatchability of eggs of Rhipicephalus (Boophilus) microplus. Biomed Res. Int. $5 p$.

Jain, K.J., Lakshmanan, B., Syamala, K., Praveena, J.E. and Aravindakshan, T. 2017. High prevalence of small Babesia species in canines of Kerala, South India. Vet. World. 10 (11): 1319-1323.

Jyothimol, G., Ravindran, R., Juliet, S., Ajithkumar, K.G., Suresh, N.N., Vimalkumar, M.B., Lenka, D.R., Varghese, S. and Ghosh, S. 2014. Low level deltamethrin resistance in ticks from cattle of Kerala, a South Indian state. Vet. Parasitol. 204(3-4): 433-438.
Kumar, S., Sharma, A.K., Nagar, G. and Ghosh, S. 2015. Determination and establishment of discriminating concentrations of malathion, coumaphos, fenvalerate and fipronil for monitoring acaricide resistance in ticks infesting animals. Ticks Tick Borne Dis. 6(3): 383-387.

Kumar, S., Sharma, A.K., Ray, D.D. and Ghosh, S. 2014. Determination of discriminating dose and evaluation of amitraz resistance status in different field isolates of Rhipicephalus (Boophilus) microplus in India. Exp. Appl. Acarol. 63(3): 413-422.

Lenka, D.R., Ravindran, R., Jyothimol, G., Udaykumar, M., Reddy, P.M.T., Sathish, N., Palla, I., Chandramohan, B., Ajithkumar, K.G., Nair, S.N. and Chandrasekhar, L. 2016. Deltamethrin resistance in South Indian isolates of Rhipicephalus (Boophilus) microplus. Vet. Parasitol. Reg. Stud. Rep. 5: 37-41.

Lovis, L., Guerrero, F.D., Miller, R.J., Bodine, D.M., Betschart, B. and Sager, H. 2012. Distribution patterns of three sodium channel mutations associated with pyrethroid resistance in Rhipicephalus (Boophilus) microplus populations from North and South America, South Africa and Australia. Int. J. Parasitol.: Drugs Drug Res. 2: 216-224.

Lovis, L., Perret, J.L., Bouvier, J., Fellay, J.M., Kaminsky, R., Betschart, B. and Sager, H. 2011. A new in vitro test to evaluate the resistance level against acaricides of the cattle tick, Rhipicephalus (Boophilus) microplus. Vet. Parasitol. 182(2-4): 269280.

Mathivathani, C., Basith, S.A., Latha, B.R. and Raj, G.D. 2011. In vitro evaluation of synthetic pyrethroid resistance in Rhipicephalus sanguineus ticks of Chennai. J. Vet. Parasitol. 25: 56-58.

Miller, R.J., Davey, R.B. and George, J.E. 2002. Modification of the food and agriculture organization larval packet test to 
measure amitraz-susceptibility against Ixodidae. J. Med. Entomol. 39: 645-651.

Morgan, J.A., Corley, S.W., Jackson, L.A., Lew-Tabor, A.E., Moolhuijzen, P.M. and Jonsson, N.N. 2009. Identification of a mutation in the para-sodium channel gene of the cattle tick Rhipicephalus (Boophilus) microplus associated with resistance to synthetic pyrethroid acaricides. Int. J. Parasitol. 39: 775-779.

Rani, S., D'Souza, P.E., Byregowda, S.M., Veeregowda, B.M., Sengupta, P.P., Chandranaik, B.M. and Thimmareddy, P.M. 2018. In vitro acaricidal efficacy of deltamethrin, cypermethrin and amitraz against sheep ticks in Karnataka. Exp. Parasitol. 201: 42-48.

Rosario-Cruz, R., Guerrero, F.D., Miller, R.J., Rodriguez-Vivas, R.I., Tijerina, M., Dominguez-Garcia, D.I., HernandezOrtiz, R., Cornel, A.J., McAbee, R.D. and Alonso-Diaz, M.A. 2009. Molecular survey of pyrethroid resistance mechanisms in Mexican field populations of Rhipicephalus (Boophilus) microplus. Parasitol. Res. 105: 1145-1153.

Sandhu, H.S. 2006. Veterinary Pharmacology and Therapeutics. (2 $\left.{ }^{\text {nd }} \mathrm{Ed}\right)$ Kalyani publisher, New Delhi, 1283p.

Santos, T.R.B., Klafke, G.M., Pappen, F.G., Nizoli, L.Q., Biegelmeyer, P. and Farias, N.A.R. 2013. Comparison of three larval bioassays to evaluate susceptibility of Rhipicephalus (Boophilus) microplus to amitraz. Rev. Bras. Parasitol. Vet. 22 . 495-501.

Sen, S.K. and Fletcher, T.B. (1962) Veterinary Entomology and Acaroligy in India, Indian Council of Agricultural Research, New Delhi.

Sharma, A.K., Kumar, R., Kumar, S., Nagar, G., Singh, N.K., Rawat, S.S., Dhakad, M.L., Rawat, A.K.S. and Ray, D.D. 2012. Deltamethrin and cypermethrin resistance status of Rhipicephalus
(Boophilus) microplus collected from six agro-climatic regions of India. Vet. Parasitol. 188: 337-345.

Shyma, K.P., Gupta, J.P., Singh, V. and Patel, K.K. 2015. In vitro detection of acaricidal resistance status of Rhipicephalus (Boophilus) microplus against commercial preparation of deltamethrin, flumethrin, and fipronil from North Gujarat, India. J. Parasitol. Res. 1-7p.

Shyma, K.P., Kumar, S., Sangwan, A.K., Sharma, A.K., Nagar, G., Ray, D.D. and Ghosh, S. 2013. Acaricide resistance status of Rhipicephalus (Boophilus) microplus and Hyalomma anatolicum collected from Haryana. Indian J. Anim. Sci. 83: 591-594.

Shyma, K.P., Kumar, S., Sharma, A.K., Ray, D.D. and Ghosh, S. 2012. Acaricide resistance status in Indian isolates of Hyalomma anatolicum. Exp Appl. Acarol. 58: 471-481.

Singh, J., Singh, N.K., Singh, H., Mehta, N. and Rath, S.S. 2019. In vitro assessment of synergistic combinations of essential oils against Rhipicephalus (Boophilus) microplus (Acari: Ixodidae). Exp. Parasitol. 201: 42-48.

Stone, B.F. and Haydock, K.P. 1962. A method for measuring the acaricide-susceptibility of the cattle tick Boophilus microplus (Can.). Bull. Entomol. Res. 53(3): 563578.

Wahlang, L., Lakshmanan, B., Thomas, N., Bosewell, A., Jose, J., Chulliyil, S. and Thazhathuveetil, A. 2019. SYBR greenbased real-time PCR detection of canine Babesia spp. in ixodid ticks infesting dogs in Kerala, South India. Turkish J. Vet. Anim. Sci. 43(3): 427-431.

Yessinou, R.E., Akpo, Y., Adoligbe, C., Adinci, J., Assogba, M.N., Koutinhouin, B., Karim, I.Y. and Farougou, S. 2016. Resistance of tick Rhipicephalus microplus to acaricides and control strategies. J. Entomol. Zool. Stud. 4(6): 408-414. 